\title{
ACTIVE PLASMA SOURCE FORMATION IN THE MAP DIODE*
}

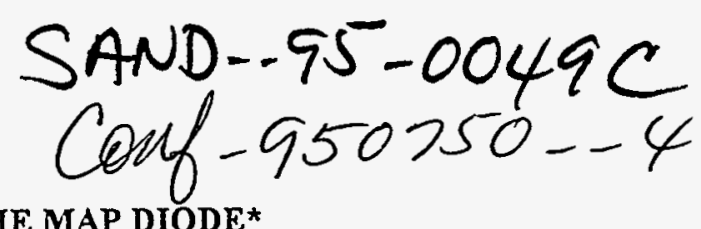

\author{
K. P. Lamppa, R. W. Stinnett, T. J. Renk, M. T. Crawford \\ Sandia National Laboratories \\ P.O. Box 5800 \\ Albuquerque, NM 87185-1193
}

\author{
J. B. Greenly: \\ Cornell University \\ Ithaca, NY 14853
}

\begin{abstract}
The Ion Beam Surface Treatment (IBEST) program is exploring using ion beams to treat the surface of a wide variety of materials. These experiments have shown that improved corrosion resistance, surface hardening, grain size modification, polishing and surface cleaning can all be achieved using a pulsed $0.4-0.8 \mathrm{MeV}$ ion beam delivering $1-10 \mathrm{~J} / \mathrm{cm}^{2}$.

The Magnetically-confined Anode Plasma (MAP) diode, developed at Cornell University', produces an active plasma which can be used to treat the surfaces of materials. The diode consists of a fast puff valve as the source of gas to produce the desired ions and two capacitively driven B-ficlds. A slow magnetic field is used for electron insulation and a fast field is used to both ionize the puffed gas and to position the plasma in the proper spatial location in the anode prior to the accelerator pulse. The relative timing between subsystems is an important factor in the effective production of the active plasma source for the MAP diode system.

The MAP diode has been characterized using a Langmuir probe to measure plasma arrival times at the anode annulus for hydrogen gas. This data was then used to determine the optimum operating point for the MAP diode on RHEPP-1 accelerator shots. Operation of the MAP diode system to produce an ion bcam of $500 \mathrm{kV}, 12 \mathrm{kA}$ with $40 \%$ efficiency (measured at the diode) has been demonstrated.
\end{abstract}

\section{INTRODUCTION}

Two recent developments in pulsed power are the enabling technologies for the IBEST program. The first is the Repetitive High Encrgy Pulsed Power 1 (RHEPP-1) accelerator. RHEPP-1 produces a $0.8 \mathrm{MV}, 17 \Omega .60$ ns FWHM pulse at up to $120 \mathrm{~Hz}$. The second is the MAP diode. The MAP system differs from well documented flashover sources because ions are drawn from a single species, preformed plasma to minimize source turn on delay and the MAP diode can be operated repetitively for a large number of shots.

\section{MAP DIODE CONSTRUCTION}

\section{Fast Puff Valve}

The fast puff valve consists of an epoxy potted 3 turn coil (Figure $1(B)$ ), two o-rings and an annular high conductivity, beryllium-copper diaphragm stamped into a conical (Belleville) shape. The Belleville shape causes the diaphragm to act as a spring during the valve operation. The puff valve is driven by a $6 \mathrm{kA}, 20 \mu \mathrm{sec}$ risetime pulse creating a magnetic field that flattens the diaphragm, allowing the gas trapped in the plenum between the orings to escape. The diaphragm then bounces off the inner anode flux excluder (D) and reseals against the o-rings. In this manner a return spring is unnecessary. The puff valve delivers approximately $1 \mathrm{~cm}^{3}$ of gas per pulse to the gas nozzle (C) formed by the inner anode flux excluder and the fast coil (I) surface.

*This work was supported by the United States Department of Energy under Contract Number DE-AC0494AL 85000 and by DOE's Advanced Energy Projects Division/Office of Basic Sciences.

\section{DISCLAIMER}

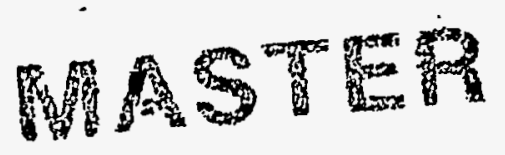

This report was prepared as an account of work sponsored by an agency of the United States Government. Neither the United States Government nor any agency thereof, nor any of their employees, makes any warranty, express or implied, or assumes any legal liability or responsibility for the accuracy, completeness, or usefulness of any information, apparatus, product, or process disclosed, or represents that its use would not infringe privately owned rights. Reference herein to any specific commercial product, process, or service by trade name, trademark, manufacturer, or otherwise does not necessarily constitute or imply its endorsement, recommendation, or favoring by the United States Government or any agency thereof. The views and opinions of authors expressed herein do not necessarily state or reflect those of the United States Government or any agency thereof. 


\section{Slow Insulating Field Coil}

The slow coil. held at cathode (ground) potential, is actually two coils ( $\mathrm{G}$ and $\mathrm{H}$ ) with the ion beam passing between them through the cathode annulus gap $(L)$. The coils are driven in series with a $12 \mathrm{kA}, 130 \mu$ s risetime pulse to provide magnetic insulation for the accelerating gap.

\section{Fast Field Coil}

The fast coil is constructed of four parallel two turn coils embedded in epoxy at $22^{\circ}$ from vertical. The coil is driven by a $45 \mathrm{kA}, 2 \mu \mathrm{s}$ risetime pulse to both ionize the gas and position the plasma prior to the arrival of the RHEPP-1 main power pulse.

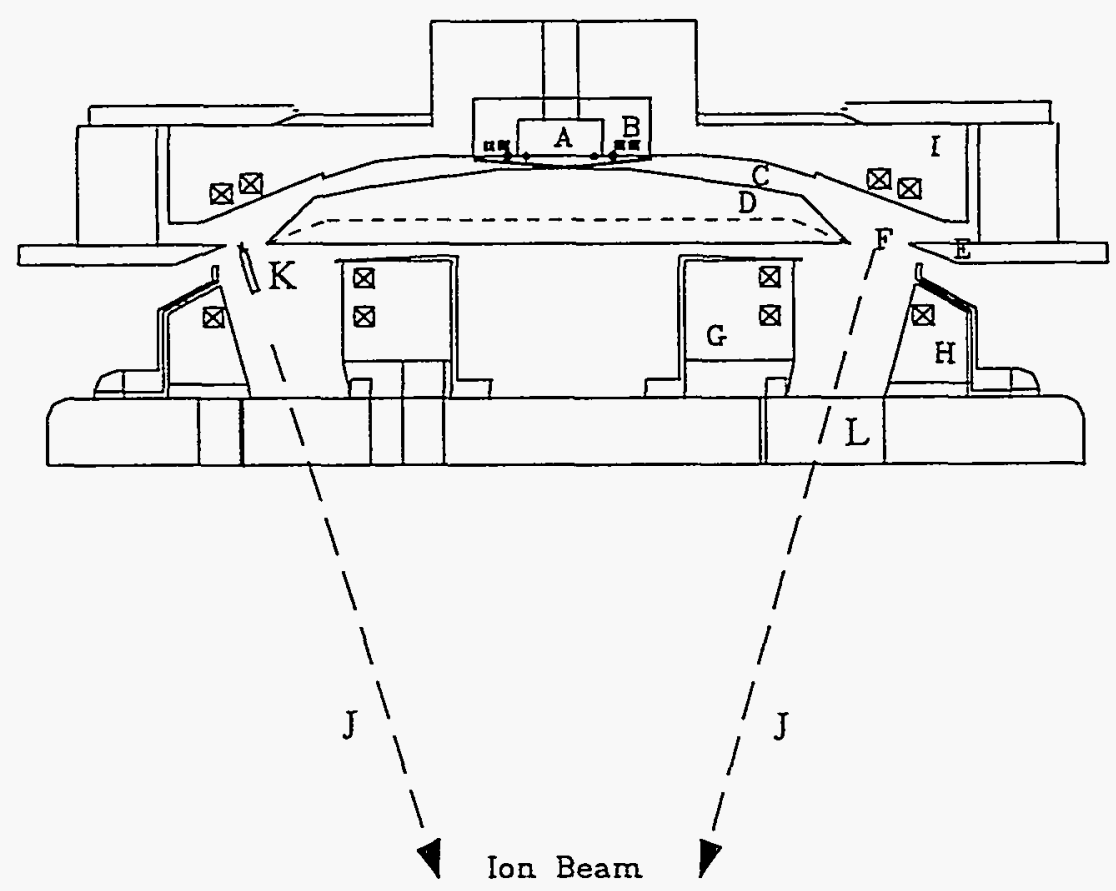

Figure 1. The MAP diode. The fast puff valve gas plenum (A) with the puff valve magnetic field coil (B): the gas delivery nozzle (C); The inner (D) and outer (E) anode flux excluders; the gas annulus for plasma formation $(F)$; the inner $(G)$ and outer $(H)$ cathode slow magnetic field coils: the fast anode magnetic field coils (I); the ion beam propagation path (J); Langmuir probe position (K); cathode annulus gap (L).

\section{FIELD INTERACTION}

The combination of the slow and fast magnetic fields provides the basis for the operation of the MAP diode. The plasma formed by the fast field is magnetically confined at the anode annulus (Figure 1, (F)) between the inner and outer anode flux excluders. Proper field profiling and timing are essential for diode operation.

The slow magnetic field is essentially static on the time scales of the fast field and the accelerator. Aluminum inner and outer anode flux excluders allow slow field penetration while excluding the fast coil flux. DiffusiveATHETA simulations, illustrated in Figure 2, show the combination of the two fields. The plasma is vertically confined between the two magnetic fields at the annulus gap where ions are extracted by the accelerator pulse. 


\section{DISCLAIMER}

Portions of this document may be illegible in electronic image products. Images are produced from the best available original document. 


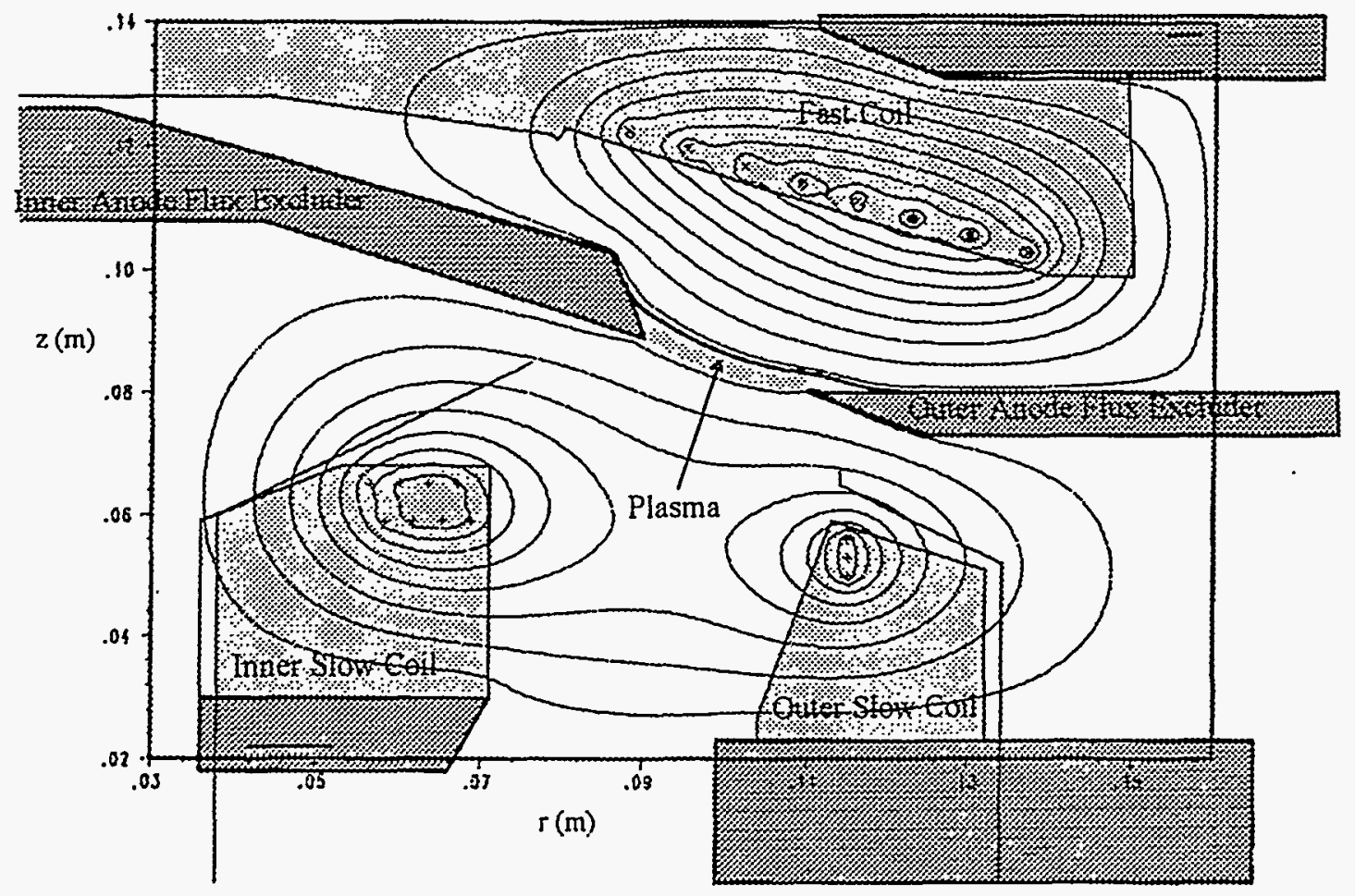

FIGURE 2. DATHETA Simulation showing the combined slow and fast magnetic field profile.

\section{LANGMUIR PROBE MEASUREMENTS}

The diode is sensitive to the relative timing between subsystems, one variable being the time delay between the puff valve and the fast coil. Using hydrogen gas and a Langmuir probe, biased at -200 VDC, plasma densities were mapped in relation to this delay. The probe tips were positioned in the center of the anode annulus gap (Figure $1,(\mathrm{~K})), 26 \mathrm{~mm}$ from the surface of the fast coil for these measurements. This distance was chosen because it is the proper radial and vertical position for ion extraction from the preformed plasma by the accelerator pulse. At delays between 0 and $130 \mu$ s the probe showed plasma arriving at $4.6 \mu$ s (Figure 3, (Q)) after the fast coil was triggered which corresponds to the first zero crossing of the fast coil current $(N)$. This implies the gas had not traveled far enough radially to be completely ionized by the rise of the fast coil current. For the MAP diode to operate correctly, the plasma needs to be fully ionized at the peak of the fast coil current to ensure proper spatial placement and confinement of the plasma at the anode annulus gap. At 130-150 $\mu$ s the plasma achieved the desired peak density 1.0-2.0 $\mu \mathrm{s}(\mathrm{P})$ after the fast coil was triggered, corresponding to the peak fast coil current and so was selected as the system operating point. At $>150 \mu \mathrm{s}$ the probes showed prompt $(O)<1.0 \mu$ s delays. This implied the gas had propagated radially to the probe tips when the fast coil fired. This delay between the puff valve and the fast coil was too long for effective diode operation since the gas was ionized before the fast field current peaked thereby prohibiting proper plasma confinement in the gas annulus. Shooting RHEPP-1 with this timing configuration resulted in the A-K gap being shorted by plasma. In this manner the operating point for the MAP diode was determined to be $130-150 \mu \mathrm{s}$. A representative shot is included as Figure 4 and discussed on the next section. 


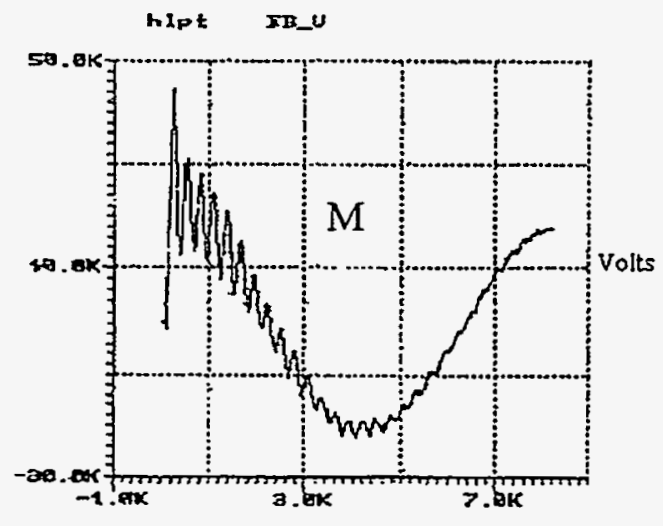

$\operatorname{sen}$ enseos

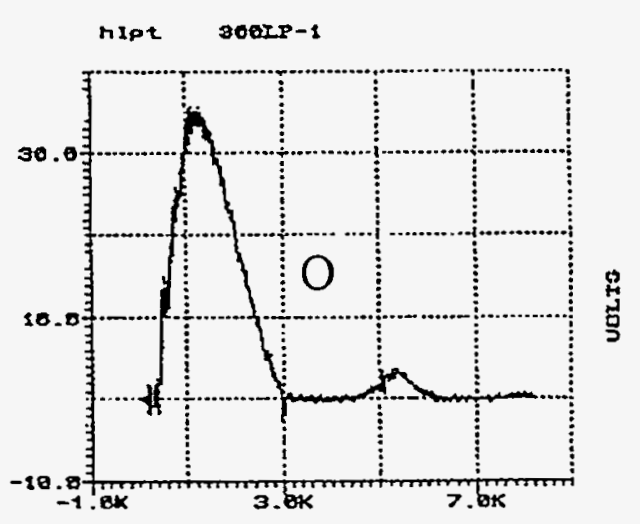

IIHE CMSEOS

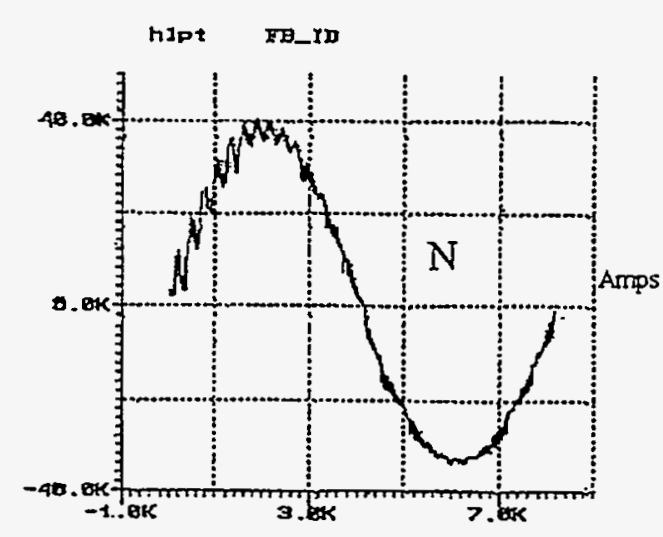

Tinz stiseas

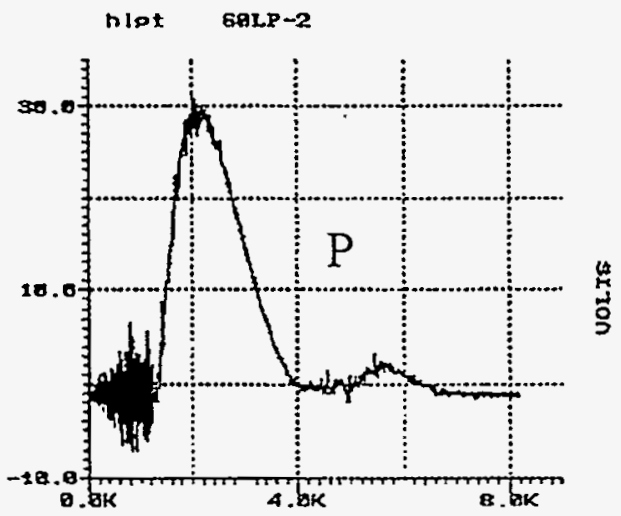

YIRE enseas

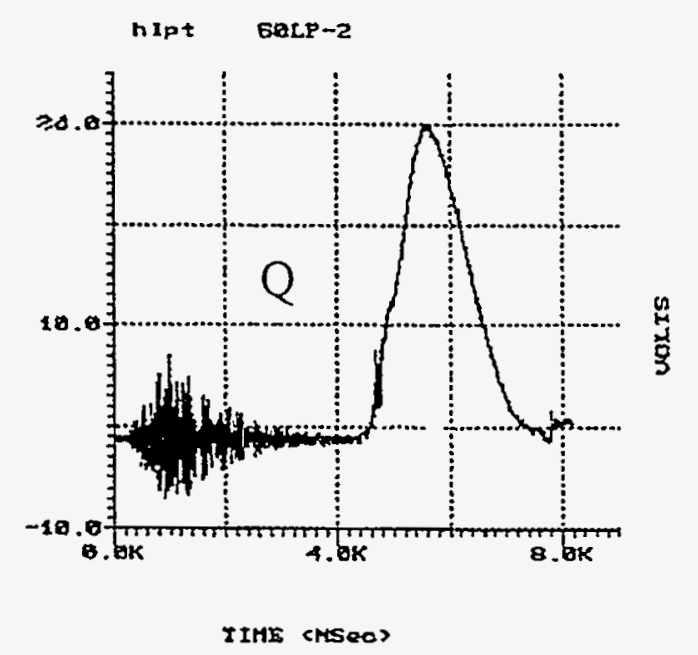

Figure 3. The fast magnetic ficld coil voltage $(M)$ and current $(N)$; a prompt (with respect to fast coil initiation) Langmuir probe signal $(\mathrm{O})$; a Langmuir probe signal with a $1.3 \mu$ s delay $(\mathrm{P})$; a Langmuir probe signal corresponding to the first zero crossing of the fast coil current $(Q)$. 


\section{OPERATION OF THE MAP DIODE SYSTEM}

The MAP diode system typically operates in the following manner for a $140 \mu$ selay between the puff valve (pressurized to $28 \mathrm{psig}$ ) and the fast coil triggers: At time 0 , the puff valve produces a localized gas volume expanding supersonically in the radial direction between the inner anode flux excluder and the fast coil surface. The slow coil is triggered to produce the insulating field. The fast coil is fired $140 \mu \mathrm{s}$ later, at the peak of the slow coil, to induce an azimuthal loop voltage on the puff valve gas volume which ionizes the gas. The rising fast field pushes the plasma to the annular gap formed by the anode inner and outer flux excluder tips where it stagnates against the slow magnetic field. RHEPP-1 is triggered $2 \mu$ s after the fast coil to extract ions from the annular plasma and geometrically accelerate them to a focus approximately $30 \mathrm{~cm}$ from the fast coil surface.

The MAP diode was characterized using the timing between the puff valve and the fast coil determined by the Langmuir probe measurements (130 - 150 $\mu$ ), and an A-K gap of $8.5 \mathrm{~mm}$. Shot MAP239 (Figure 4) is representative of this series. This shot showed, at peak diode power, a $550 \mathrm{kV}, 12 \mathrm{kA}$ ion beam at the diode with an impedance of $20 \Omega$ (Figure 5 (AA)). The efficiency was calculated to be $40 \%$ (BB) from the diode power and ion power. A preformed plasma is shown to be at the annulus (properly located for ion extraction) by the ion current rising at the same time as the corrected voltage. Other shots showed efficiencies from $30-70 \%$ and ion energies up to $800 \mathrm{~J}$.

Faraday cups, biased at $-200 \mathrm{VDC}$ and mounted in the cathode annulus gap, showed $50-250 \mathrm{~A} / \mathrm{cm}^{2}$ (Figure $6(\mathrm{CC}))$. Cups at the treatment platform $\left(35 \mathrm{~cm}\right.$ from the surface of the fast coil) indicated $75 \mathrm{~A} / \mathrm{cm}^{2}$ at the approximate center of the beam and $40 \mathrm{~A} / \mathrm{cm}^{2} 3.6 \mathrm{~cm}$ from the center faraday cup (DD). A polished aluminum witness plate showed a $10 \mathrm{~cm}$ beam damage diameter at the treatment platform.
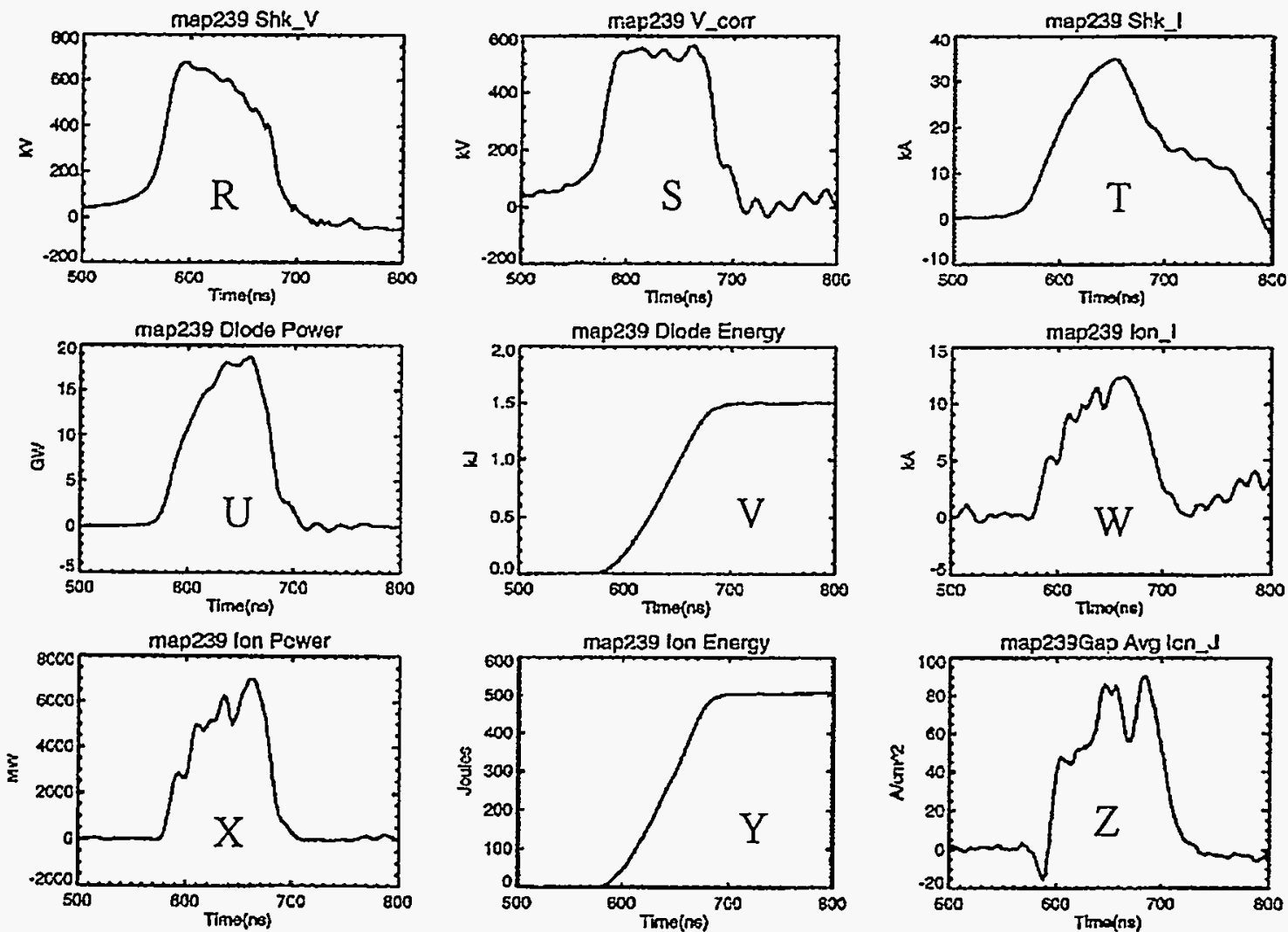

Figure 4. The RHEPP-1 accelerator shank voltage (R); the MAP corrected diode voltage (S); the RHEPP-1 shank current (T); the MAP diode power $(U)$, energy $(V)$, ion current $(W)$, ion power $(X)$, ion energy $(Y)$; the average cathode annulus gap faraday cup current density $(Z)$. 

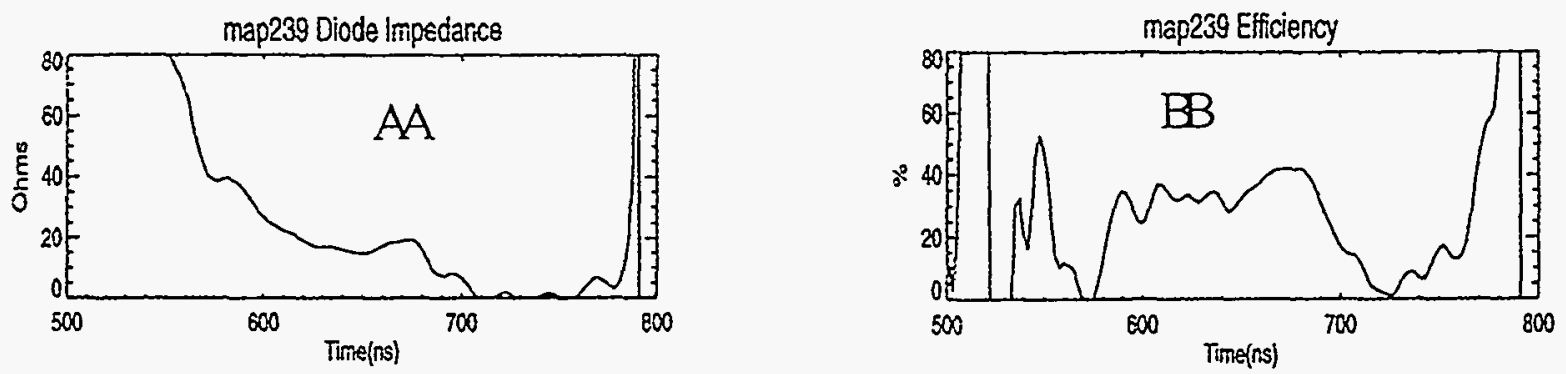

Figure 5. MAP diode impedance (AA) and efficiency (BB).
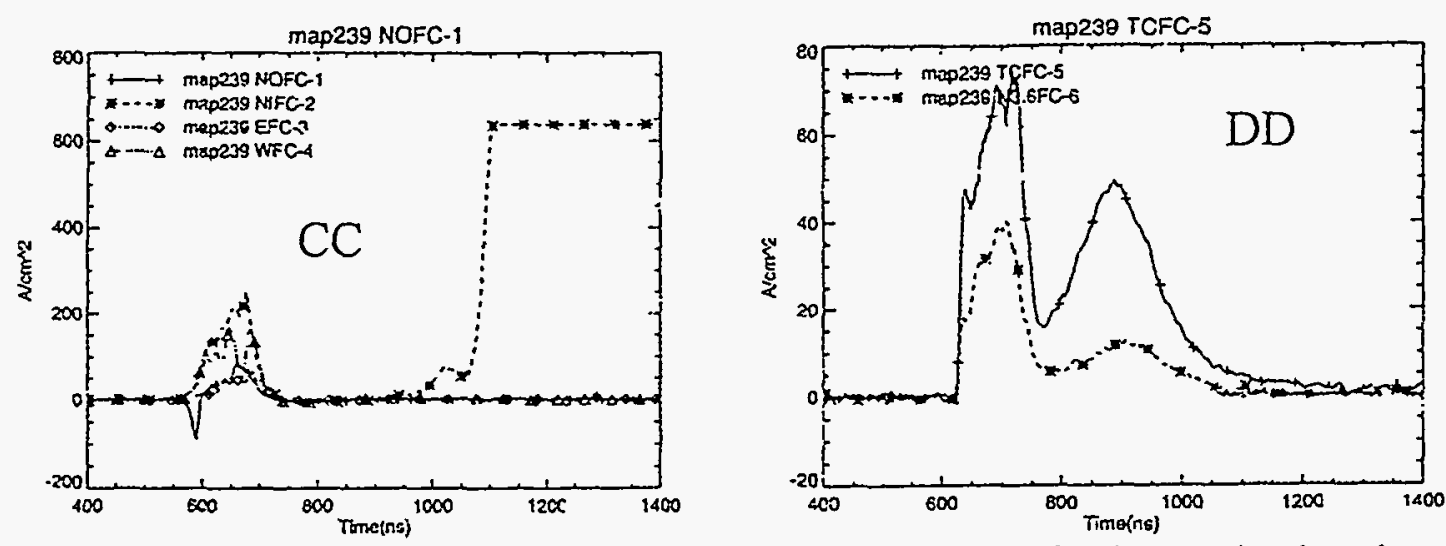

Figure 6. Faraday cup signals measured in the cathode annulus gap (CC); faraday cup signals at the treatment platform $35 \mathrm{~cm}$ from the surface of the fast coil (DD). TCFC = center faraday cup, $\mathrm{N} 3.6 \mathrm{FC}=3.6 \mathrm{~cm}$ north from the center cup

\section{CONCLUSIONS}

Langmuir probe measurements of the arrival times of plasmas, produced from hydrogen gas, showed the optimum time delay between the puff valve and the fast coil to be $130-150 \mu$ s. This timing was used on a series of MAP diode shots to produce ion beams of $500 \mathrm{kV}, 12 \mathrm{kA}$ and with $40 \%$ efficiency. The ion beams produced are sufficient to treat materials with the MAP diode for initial material science experiments for the IBEST program.

\section{DISCUSSION}

Other shots in this series produced corrected diode voltages of $250-650 \mathrm{kV}, 10-30 \mathrm{kA}$ ion current and efficiencies from $30-70 \%$. Calculations of beam composition showed the beam was composed of approximately $40 \%$ carbon and $60 \%$ protons. This is evidenced by the double peaks in the cathode annulus gap faraday cup signals (Figure $5(A)$ ). The energics associated with each of these constituents was $3 \mathrm{~J} / \mathrm{cm}^{2}$ for protons and $1 \mathrm{~J} / \mathrm{cm}^{2}$ for carbon measured at the treatment platform in the center of the beam. The protons are produced at peak diode corrected voltage ( $500 \mathrm{kV}$ for shot MAP239) while the carbon ions are produced later in the pulse when the diode voltage was rapidly falling (approximately $300 \mathrm{kV}$ for MAP239). Also, pinhole camera images show that although ions were produced at all azimuthal locations, the ion intensity was not uniform at all positions. Further investigation is underway to determine the mechanism for carbon ion production, increase beam purity and to improve uniformity and reproducibility.

\section{References}

1. J. B. Greenly, L. Brissette, A. Dunning, S. C. Glidden, D. A. Hammer and W. A.Noonan, Proc. of the 8th Int'1 Conf. on High Power Particle Beams, B.N. Breizman and B.A. Knyazev, Eds., Novosibirsk, 1990 (World Scientific), p. 199. 